\title{
Comparative Effect of Participation in Different Sports on Quality of Life Perception by Inmates of Ilesa Prison in Osun State of Nigeria
}

\author{
Honestus Ayobami Obadiora \\ Department of Physical \& Health Education, Obafemi Awolowo University, Ile-Ife, Nigeria \\ Email address: \\ ayobadiora@yahoo.com \\ To cite this article: \\ Honestus Ayobami Obadiora. Comparative Effect of Participation in Different Sports on Quality of Life Perception by Inmates of Ilesa \\ Prison in Osun State of Nigeria. International Journal of Sports Science and Physical Education. Vol. 3, No. 1, 2018, pp. 9-15. \\ doi: $10.11648 /$ j.ijsspe.20180301.12
}

Received: February 3, 2018; Accepted: February 24, 2018; Published: March 29, 2018

\begin{abstract}
Lack of empirical evidence on the influence of sports in the promotion of inmates' quality of life and their rehabilitation is posing serious challenge to effective use of sports in correctional programmes. This study focused on the effects of different sports on the QOL among inmates in Ilesa Prison in Osun State of Nigeria. The study employed experimental pretest - posttest control research design. This study was carried out over a 10 week period at the Ilesa prison in Osun State, Nigerian. 140 inmates were selected for the study. The respondents were grouped into four sports- athletics, badminton, table-tennis and volleyball. The World Health Organization Quality of Life Scale (WHOQOL-BREF) was adapted and used to determine the QOL of inmates across different sport groups. The data collected on reported quality of life condition of inmates against the different categories of sport participation (athletics, badminton, table-tennis and volley-ball) were analysed with descriptive and inferential statistics. Multiple regression analysis and Analysis of variance (ANOVA) were used to determine whether differences observed on the QOL perception of inmates and participation in different sports are significant. The findings showed that there is a relationship between participation in different sports and quality of life. The result of ANOVA showed that the calculated F-ratio of 12.865 for inmates perception of their quality of life after participation in different sports was significant at $\mathrm{p}=0.000$ when tested at 0.05 level of significance. The results of multiple regression showed that quality of life of the prisoners' increases as they participated in volley ball $(\beta=0.908)$, badminton $(\beta=1.321)$, Table Tennis $(\beta=1.521)$ and athletics $(\beta=7.401)$. It was concluded that participation in different sport presents similar and positive effect on the quality of life perception among inmates of Ilesa prison in Nigeria.
\end{abstract}

Keywords: Inmates, Prison, Sport, Social, Wellbeing, Quality of Life

\section{Introduction}

The establishment of prisons in Nigeria is backed by various statutes from the colonial period to the present. Among these statutes are the Prisons Ordinance of 1916; The Laws of Nigeria of 1948 and 1958; and the Prison Decree No. 9 of 1970. A Government White Paper in 1971 outlined the functions of the prison service to include: custody, diagnosis, correction, training and rehabilitation of incarcerated offenders. The Nigerian Prisons Service (NPS) was founded as an institution to correct social deviants, punish and reform criminals and to complement the processes of legal adjudication and law enforcement [1]. Prisons are therefore meant to be reformatory homes, where persons who come in conflict with the law are sent to for reformation and eventually reintegrated into the society as a better person. A major issue that affects offenders' welfare is the respect for the rights of inmates despite their incarceration [2]. Some of these violations include; provision or insufficient treatment for serious medical conditions; poor feeding; lack of adequate health education on disease control; and denial of conjugal visits, denial of assess to sport and education just to mention but a few. Thus, the employment of specialists like sport and physical fitness teacher, psychologists, social workers, and health care providers as prison officers was a significant symbolic step in many countries towards the provision of 
inmates' balanced needs $[3-6,7]$.

\section{Concept of Quality of Life}

Quality of life is defined as the perception of individuals, of their position in life in the context of culture and value systems accepted by the society in which they live and in relation to their life goals, expectations, or interests [8]. This definition emphasizes the subjective dimension of quality of life, considering that the individual is a being who is able to determine the quality of his/her own life referring to his/her own assessments. Quality of life is a state of wellbeing which is a composite of two components: first, the ability to perform everyday activities which reflects physical, psychological, and social well-being and second, patient satisfaction with levels of functioning and the control of disease and/or treatment related symptoms [9]. Also, Quality of Life was defined as an individual's perception of their position in life in the context of the culture and value systems in which they live and in relation to their goals, expectations, standards and concerns [10]. It is a broad ranging concept affected in a complex way by the person's physical health, psychological state, personal beliefs, social relationships and their relationship to salient features of their environment [10]. Much of the quality of life debate remains over what domains influence quality of life. The World Health Organization defined quality of life as 'individuals' perception of their position in life in the context of the culture and value systems in which they live and in the relation to their goals, expectations, standards and concerns" and includes physical, psychological, and social wellbeing as the minimum dimensions [11]. The concept was further defined by broad indicators, to include the natural and social environment, opportunities, and services available to people living in a particular area [12]. It was noted that prison environments have a bearing on inmates' quality of life [7].

\section{Sport and Inmates' Quality of Life}

Sport programmes can provide a cost-effective, meaningful and effective vehicle through which inmates' wellbeing can be positively affected. Their positive social changes, skills development and rehabilitation/ reintegration can be achieved through organised sport as many findings supported the role of sport for achieving educational, health and social goals [1415]. There is a long established theoretical believe on the importance of sport on wellbeing [16]. Sport is found effective in promoting physical, social, emotional and psychological wellbeing of participants. Since, prison inmates have also been discovered to possess emotional, psychological and physical health challenges due largely to their confinement inside prison facilities, involvement in sport activities is therefore considered crucial for effective development of quality of life including healthy personality of inmates [17-18]. Sports participation is believed to be effective in promoting physical health, psychological and social wellbeing perception of general and clinical population including those in correctional homes [19-20].

Within the social context of prison programme, participation in sports facilitates adequate socialization into the sports and socialization through sports. Therefore, the greater the amount of success achieved during sport involvement process, the higher the ability of the learner to achieve social skills and cohesions and enhancement of self-concept and positive personality. It was observed that general population can be influenced by the potent-power of sport as an instrument for physical, social, psychological, environmental and general wellbeing [21]. Also, many research findings revealed that individuals engaged in sport activities show more selfdependence and confidence [22-23].

\section{The Study Conceptual Framework}

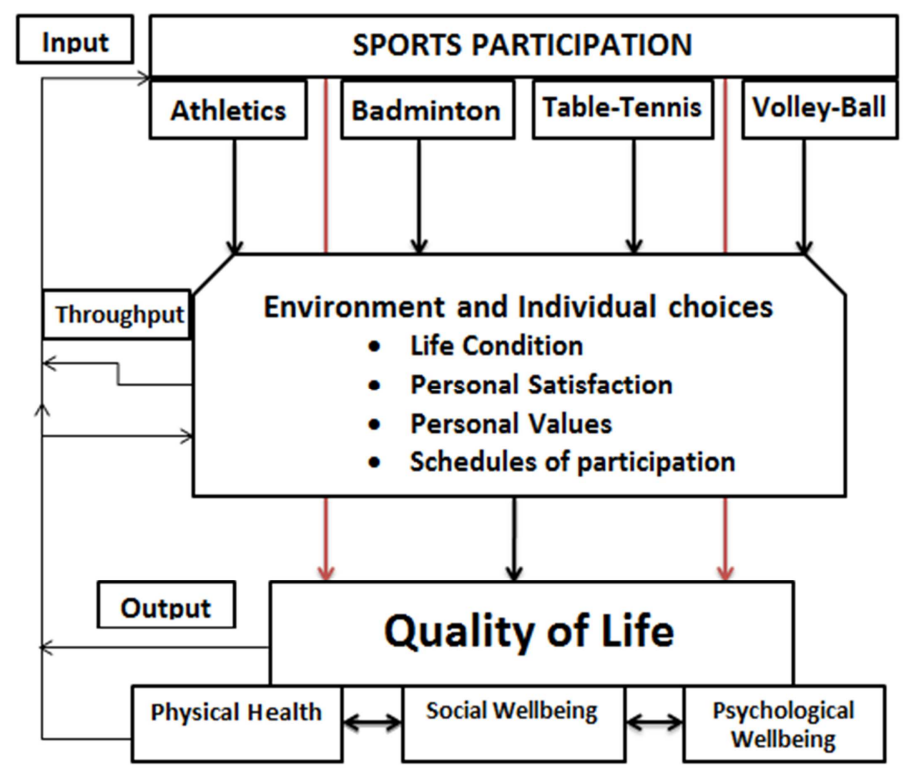

Figure 1. Conceptual Framework of Influence of Sports Participation on Quality of Life. 
The conceptual framework of this study is illustrated in the figure 1 below. The figure describes the study processes from the input (sports participation) and the output (effect on quality of life perceptions). The treatment group participated in sports while the control groups only observed the participation. The throughput are the internal (individual) and external (environmental) factors that affect participation and the output such as schedule of participation and life choices and preferences. The output in the framework is the change in the QOL perception and in each of the three investigated domains of physical, social and psychological wellbeing [7].

\section{Materials and Methods}

\subsection{Study Setting}

The Nigerian Prisons Service, Ilesa Prison Yard, Ilesa, Osun State, Nigeria is a medium security facility, adjacent to Ilesa Police Area Command Headquarters in Ayeso, Ilesa East Local Government Area of Osun State. Ilesa Prison facility was commissioned in 1943 with capacity to accommodate 600 inmates while the 2013 number of inmates is put at about 526. Despite the population of the inmates which was below the prison capacity, beds and bedding in the prisons were inadequate. In some cells or prison blocks where beds are available, mattresses, bed sheets and blankets were lacking. The prison has an open space of about 60 by 80 $\mathrm{m}$ size meant for recreational sports and physical activities. The prison yard lacks basic equipment for sporting activities hence the playing field is hardly put into use.

\subsection{Type and Period of Study}

The study employed experimental pretest - posttest control research design. A total of 140 respondents were selected through purposive sampling technique. The study covered a period of ten weeks. The first week was used to administer QOL pretest instrument, the following eight weeks were used for participation in sport. The eight weeks included two weeks of teaching on theory and techniques of sports-skills, rules and regulations and officiating as well as six weeks used by within sport group practice and tournament sessions. The last week of the study was used for the administration of QOL post-test instrument.

\subsection{Population and Sample Size}

The study population comprised male inmates in Ilesa Prison. Study respondents were selected using systematic random sampling technique. The study samples were 140 inmates within age 20 and 35 years, excluding inmates on death sentence and those undergoing medical and/or psychiatric treatment. Inmates within the age range were selected because young adulthood typically covers the period from 20-35 years of age, when both biological function and physical performance reach their peak [24]. The respondents were randomised into two groups of experimental and control to facilitate comparison of collected data. The study excluded inmates on death sentence or those undergoing medical and/or psychiatric treatment.

\subsection{Data Collection}

The WHOQOL-BREF scale was used to measure the QOL perceptions among inmates of Ilesa prison. The instrument was developed by WHO and simultaneously tested in diverse cultures across the world, this means that the instrument has a strong potential for easy cross-cultural applicability [10]. The scale includes widely valued contextual factors of life that are not generally regarded as health-related. Therefore, it is a generic instrument that assesses QOL [10]. The instrument is a 26-item, self-administered, generic scale [25]. The response options range from 1 to 5 . It consists of QOL domains of physical health (seven items), psychological health (six items), social relations (three items) and environment (eight items). The scale is used to determine the inmates' quality of life perception in this study.

\subsection{Ethical Considerations}

The study was approved by the academic and postgraduate committees of the Obafemi Awolowo University as a doctorate requirement. Also, the study was approved by the State Comptroller of the Osun State Command of Nigeria Prison Service (NPS) following the advice of the command's legal officer. The study obtained a voluntary and written consent of the inmates to participate in the study. The inmates are fully aware of their right to withdraw from the study at any time during the period of the study.

\subsection{Data Analysis}

The data collected were analysed against each of the age categories (20-27 and $28-35$ years) of the respondents with descriptive and inferential statistics. Regression analysis, pearson's product moment correlation coefficients and analysis of variance (ANOVA) was used to determine whether differences observed on the interactive effects of age and sports participation on the perceived physical health, social and psychological wellbeing domains of QOL measurements among the inmates are significant. Statistical significance for the analyses was set at $\mathrm{P}<0.05$.

\section{Results}

The study investigated the quality of life perception among inmates of Ilesa prison before and after participation in different sport activities. Three domains of quality of lifewhich are physical health, social wellbeing and psychological wellbeing were investigated. The comparative effects of participation in different sport activities (athletics, badminton, table-tennis and volleyball) on quality of life were tested.

Table 1 shows the mean and standard deviation scores of quality of life of inmates in Ilesa prison. The mean and Standard Deviation of the quality of life scores of subjects in 
control and experimental groups by sub-groups of athletics, badminton, table tennis and volleyball were presented. The table showed that that there is no significant difference in the quality of life perception among experimental $(\mathrm{M}=66.26$, SD $=18.63)$ and control groups $(\mathrm{M}=66.53, \mathrm{SD}=19.62)$ before sport participation. However, it was observed that though, post-test mean scores of both experimental and control groups increased, the difference in the pre-test and post-test mean scores $(M=99.63, \mathrm{SD}=18.23)$ of experimental group is significant while there is no significant difference between the pre-test and post-test mean scores of the control groups $(\mathrm{M}=82.73$, SD =16.97). It was therefore concluded that differences observed in the post-test scores of inmates in experimental group was due to participation in sport activities.

Also, further analysis using the Pearson's Product Moment Correlation Coefficients of Sport Participation and Perceived Quality of Life of inmates in Ilesa Prison is shown in Table 2. The Correlation Coefficients of relationship between Sport Participation and Perceived Quality of Life of subjects in sub-groups of athletics, badminton, table tennis and volleyball were presented. The table shows a positive relationship between different sports (athletics, badminton, table tennis and volleyball) and quality of life.

Table 1. Mean and standard deviation of pre-test and post-test scores of quality of life perception.

\begin{tabular}{|c|c|c|c|c|c|c|c|}
\hline \multirow{3}{*}{ Elements } & & \multicolumn{6}{|c|}{ Sports Participation (Athletics, Badminton, Table-Tennis and Volley-Ball) } \\
\hline & & \multicolumn{3}{|c|}{ Experimental $(n=70)$} & \multicolumn{3}{|c|}{ Control $(n=70)$} \\
\hline & & Pre & Post & Mean Diff* (pre-post) & Pre & Post & Mean Diff* (pre-post) \\
\hline \multirow{2}{*}{ Global QOL } & M & 66.26 & 99.63 & $33.37(50.4 \%)$ & 66.53 & 82.73 & $16.2(24.3 \%)$ \\
\hline & $\mathrm{SD}$ & 18.627 & 18.229 & & 19.621 & 16.969 & \\
\hline \multirow{2}{*}{ Physical Health } & M & 19.33 & 32.59 & $13.26(68.6 \%)$ & 18.87 & 23.04 & $4.17(22.1 \%)$ \\
\hline & SD & 5.597 & 5.802 & & 6.281 & 5.262 & \\
\hline Psychological Wellbeing & $\mathrm{SD}$ & 4.889 & 5.192 & & 5.386 & 5.073 & \\
\hline \multirow{2}{*}{ Social Wellbeing } & M & 27.77 & 36.40 & $8.63(31.1 \%)$ & 28.79 & 36.69 & $7.9(27.4 \%)$ \\
\hline & $\mathrm{SD}$ & 9.239 & 8.566 & & 9.086 & 8.354 & \\
\hline
\end{tabular}

It was observed in Table 2 that there is a moderate correlation between participation in athletics and quality of life $(\mathrm{r}=0.554)$ which is significant at $(\mathrm{P}<.01)$. It is therefore concluded that relationship between athletics and quality of life is statistically significant. It was further observed that there is a weak correlation between participation in badminton and quality of life ( $\mathrm{r}=.424)$ which is significant at $(\mathrm{P}<.01)$. However, there is a modest correlation between participation in Table Tennis and quality of life $(\mathrm{r}=6.32)$ which is significant at $(\mathrm{P}<.01)$ while there is a weak correlation between volleyball participation and quality of life $(\mathrm{r}=.437)$ which is significant at $(\mathrm{P}<.01)$. It is therefore concluded that there is a positive and statistically significant relationship between participation in different sports and quality of life among inmates of Ilesa prison.

Table 2. Pearson's Product Moment Correlation Coefficients of Sport Participation and Perceived Quality of Life by Sport Group

\begin{tabular}{llllll}
\hline \multirow{2}{*}{ Group-Sport Participation } & Correlations & & & \\
\cline { 2 - 6 } & Physical Health & Psychological Well Being & Social Well Being & General Quality of Life \\
\hline \multirow{2}{*}{ Athletics } & Pearson Correlation & $.685^{* *}$ & $.576^{* *}$ & $.272^{*}$ & $.554^{* *}$ \\
\multirow{2}{*}{ Badminton } & Sig. (2-tailed) & .000 & .000 & .030 & .000 \\
\multirow{4}{*}{ Table Tennis } & Pearson Correlation & $.555^{* *}$ & $.544^{* *}$ & .163 & $.424^{* *}$ \\
& Sig. (2-tailed) & .000 & .000 & .197 & .000 \\
\multirow{2}{*}{ Volleyball } & Pearson Correlation & $.697^{* *}$ & $.773^{* *}$ & $.373^{* *}$ & $.632^{* *}$ \\
& Sig. (2-tailed) & .000 & .000 & .005 & .000 \\
& Pearson Correlation & $.504^{* *}$ & $.497^{* *}$ & $.248^{*}$ & $.437^{* *}$ \\
& Sig. (2-tailed) & .000 & .000 & .015 & .000 \\
\hline
\end{tabular}

$\mathrm{P}<0.01$.

Table 3 shows Analysis of Variance (ANOVA) of the relationship between sport participation and quality of life of inmates in Ilesa prison. The quality of life perception is the result of the responses obtained to items that elicited information on perceptions of inmates about their physical health, psychological wellbeing and social wellbeing in Ilesa Prison. All the results of the subjects in experimental and control groups were merged and analysed.

ANOVA was used to test if the differences observed in the quality of life (physical health, psychological and social wellbeing) perceptions of inmates in Ilesa Prison were statistically significant. Table 2 shows that the calculated Fratio of 12.865 for inmates perception of their quality of life was significant at $\mathrm{p}=0.000$ when tested at 0.05 level of significance. The findings show that there is a relationship between sport participation and quality of life perception in Ilesa Prison. 
Table 3. Result of analysis of variance of the relationship between sport participation and quality of life.

\begin{tabular}{|c|c|c|c|c|c|}
\hline \multicolumn{6}{|l|}{ ANOVA } \\
\hline \multicolumn{6}{|c|}{ General Quality of Life } \\
\hline & Sum of Squares & Df & MS & $\mathbf{F}$ & Sig. \\
\hline Between Groups & 47331.880 & 10 & 4733.188 & 12.865 & .000 \\
\hline Within Groups & 98971.263 & 269 & 367.923 & & \\
\hline Total & 146303.143 & 279 & & & \\
\hline
\end{tabular}

$\mathrm{P}<0.05$.

Further analysis of the relationship between sport participation and quality of life of inmates were done using Multiple Regression Analysis as shown in Table 4. The results of multiple regression shows that quality of life of the prisoners' increases as they participated in athletics $(\beta=$ 7.401). Furthermore, the result of the t-test shows that the contribution of athletics in increasing the physical heath of the inmates is statistically significant $(p=.001)$. Findings further revealed that prisoners quality of life $(\beta=1.321)$ increases with an increase in participation in badminton. Similarly, the contribution of this sport to prisoners' quality of life is statistically significant. The result of t-test $(\mathrm{t}=$ $6.911 ; p=.000$ ) confirmed this. Likewise, the results of multiple regression shows that participation of inmates in Table Tennis increases their quality of life $(\beta=1.521)$. The result of the t-test further shows that the contribution of Table Tennis in increasing the inmates' quality of life is statistically significant. This was significant at $(\mathrm{t}=9.403 ; p=.000)$. The results of multiple regression shows that quality of life of the prisoners' increases as they participated in volley ball $(\beta=$ 0.908). Furthermore, the result of the t-test shows that the contribution of volley ball in increasing the quality of life of the inmates is statistically significant $(p=.000)$. In order to determine the actual contribution of sport generally to inmates' quality of life, a linear regression was computed as shown in Table 4. The results of linear regression shows that quality of life of the prisoners' increases as they participated in sports $(\beta=18.901)$. Furthermore, the result of the t-test shows that the contribution of sport to quality of life of the inmates is statistically significant at $(\mathrm{t}=13.688 ; p=.000)$.

The cumulative $R$-square for these entire sport variables was put at 0.752 . The coefficient of determination (R-square) indicates that the model adequately fit the data. This implies that about $75.2 \%$ variance in quality of life of the inmates was explained by all the predictors variables entered into the regression model while the remaining $24.8 \%$ error term indicated that there were other important explanatory variables (aside those sports considered in this study) pertaining to inmates' quality of which could be explored in future analysis. The coefficient of explanation $(R 2=0.752)$ was used to develop useful multiple and linear regression models in explaining quality of life of the inmates. The model derived is presented thus;

$$
\mathrm{Y}=30.102+7.401 \mathrm{X}_{1}+1.321 \mathrm{X}_{2}+1.521 \mathrm{X}_{3}+0.908 \mathrm{X}_{4}
$$

Where; $Y=$ Quality of Life,

$\mathrm{X}_{1}=$ Athletics, $\mathrm{X}_{2}=$ Badminton, $\mathrm{X}_{3}=$ Table Tennis and $\mathrm{X}_{4}$ $=$ Volley Ball.

$$
\mathrm{Y}=30.102+18.901 \mathrm{X}
$$

Where; $Y=$ Quality of Life and $\mathrm{X}=$ Sport Participation

\begin{tabular}{|c|c|c|c|c|c|c|}
\hline \multirow[t]{2}{*}{ Model } & & \multicolumn{2}{|c|}{ Unstandardized Coefficients } & \multirow{2}{*}{$\begin{array}{l}\text { Standardized Coefficients } \\
\text { Beta }\end{array}$} & \multirow[b]{2}{*}{$\mathbf{t}$} & \multirow{2}{*}{ Sig. } \\
\hline & & $\beta$ & Std. Error & & & \\
\hline \multirow[b]{6}{*}{ Linear Regression } & (Constant) & 32.102 & 4.621 & .017 & 6.411 & 0.001 \\
\hline & Athletics & 7.401 & 0.465 & -.286 & 10.107 & 0.001 \\
\hline & Badminton & 1.321 & 1.431 & .084 & 6.911 & 0.000 \\
\hline & Table-Tennis & 1.521 & 0.982 & -.422 & 9.403 & 0.000 \\
\hline & Volley Ball & 0.908 & 7.212 & .017 & 8.699 & 0.000 \\
\hline & Sport Participation & 18.901 & 0.109 & -.786 & 13.688 & 0.000 \\
\hline
\end{tabular}

Table 4. Coefficients of regression analysis between Sport participation and inmates' perception of their quality of life.

p. $<0.05$.

a. Dependent Variable: Quality of Life

Based on the observed relationship between sport participation and perception of inmates about their quality of life, it is concluded that there is a positive relationship between participation in all the sport activities (athletics, table-tennis, badminton and volley-ball) and inmates' perception of their quality of life in Ilesa Prison.

\section{Discussion}

The study investigated the effects of participation in different sports on the quality of life perception among inmates of Ilesa prison in Osun State of Nigeria. The World Health Organisation's Quality of Life Brief (WHOQOLBRIEF) instrument was used for the study. The adapted QOL instrument measured the global QOL and the three QOL domains of physical health, social and psychological wellbeing. The result of the analysis of the relationship between participation in different sports and quality of life among inmates showed a moderate relationship. However, the ANOVA analysis showed a significant effect of 
participation in different sport on quality of life. It was also discovered through a regression analysis that participation in different sporting activities increases the level of quality of life among the respondents. The study concluded that participation in different sports affect the quality of life perception of inmates in Ilesa prison in Osun State of Nigeria. The findings of this study agreed with the observation of [26] that the physical activity and QOL relationship is positive and is consistent across subgroups, activity settings, and activity mode, despite an array of measures being used to assess multidimensional QOL. The result of this study further showed that quality of life including all the measured domains of physical, social and psychological health increases with participation in different sport activities by the inmates of Ilesa prison in Osun State. This finding agrees with [27] that physical activity is associated with improvements in four broad areas: enhanced mood, stress reduction, a more positive self-concept, and a higher quality of life. The findings of this study further confirmed the observation of $[23,28]$ that well-structured, organised sport and recreational activities are effective in the psychological treatment and social rehabilitation of prison inmates and patients with personality disorder in a resourcepoor setting.

\section{Conclusion}

There are sufficient results of various studies that showed that well-structured, organised and modified sports and physical activities can improve the quality of life- physical health, social and psychological needs of general population including convalescent patients. Recent studies confirmed that sport participation present similar effect on prison inmates. It is also hoped that social and psychological benefits of sport participation on the inmates will be transferred to the wider social context and reduce recidivism that may lead to prison re-entry. Further research is recommended on the influence of sport on postimprisonment behaviour and QOL.

Limitations of the study

The respondents were limited to male inmates within the age of 20 and 35 years for maximum participation. More than 48 percent of inmates below 20 and above 35 years were excluded from the study due to age. The results of the study may not be applicable to female prisoners and male inmates outside the age between 20 and 35 years.

\section{Conflict of Interests}

The author declares that he does not have any possible conflicts of interest.

\section{Acknowledgements}

The author expressed his appreciation to the following people: Professor Samuel Oluwole Salokun (my doctoral thesis supervisor), Professor Akin Ogunlade, Dr. Joseph
Adebayo Obadiora, Dr. Wumi Israel Badiora and Mr. Afolabi Adekola for providing technical supports to this study.

\section{References}

[1] FGN, Federal Government of Nigeria Prisons Act CAP 366; Laws of the Federation of Nigeria. Suleja: JASCO press, 1990.

[2] King, S., "Prison- A New or Renewed Response to Crimes?" paper Presented at the 4th National Outlook Symposium on Crime in Australia, New Crimes or New Responses Convened by the Australian Institute Criminology and held in Canberra, from 21st to 22nd June, 2001.

[3] Thomas, JE, The English Prison Officer since 1850. London. Routledge and Kegan Paul, 1972.

[4] Hill, I. (1988) The Professional Role of Prison Officers, in D. Biles (ed.), Current Australian Trends in Corrections, Sydney: Federation Press. 8-14.

[5] O'Brien P. (1998) "Prison on the Continent, Europe 18651965 " in N. Morris and D. J. Rothman, The Oxford History of the Prison. Oxford University Press, Oxford; 203-231.

[6] Enuku-Evawoma U., Humanizing the Nigerian Prison Through Literacy Education: Echoes from Afar. JCE March, 2001, 52 (1). Available at

http://www.nwlincs.org/correctional_education/articles/nigeria nprison-enuku.pdf., accessed on $2^{\text {nd }} \bar{S}$ September, 2017.

[7] Obadiora, A. H. (2017) "Effect of Sport Participation on Quality of Life among Inmates of Ilesa Prison". A project thesis submitted in partial fulfilment of the requirements for the award of Doctor of Philosophy in Physical Education of the Obafemi Awolowo University, Ile- Ife, Nigeria, 2017.

[8] Rokicka E., 'The Concept of 'Quality of Life' in the Context of Economic Performance and Social Progress in D. EiBel et al. (eds.), Welfare State at Risk. Springer, Switzerland, 2014.

[9] Marcel W. M. (2014) Definitions of Quality of Life: What Has Happened and How to Move On, Topics in Spinal Cord Injury Rehabilitation, 20 (3):167-180.

[10] WHO (1998) WHOQOL User Manual. Division of Mental Health and Prevention of Substance Abuse. World Health Organization, Geneva, Switzerland, 1998.

[11] WHOQOL Group (1995) The World Health Organization Quality of Life Assessment (WHOQOL): Position paper from the World Health Organization. Social Science and Medicine, 1995, 41, 1403-1409.

[12] Benson, J. F., \& Roe, M. H., Landscape and sustainability. Abingdon, Oxon: Routledge, 2007.

[13] WHO (1996) World Health Organization Quality of Life Assessment Instrument. Short Version (WHOQOL-Bref).

[14] Charles, A. T., Social Interaction in Nigerian Prison. (Unpublished M. Sc Thesis, Department of Sociology, A. B. U., Zaria, 1988.

[15] Patriksson, G. (1995) Sport et activité physique, in CDDS, Le rôle du sport dans la societé: santé socialisation, économie. Strasbourg: Les éditions du Conseil de l'Europe, 123-142. 
[16] UK Ministry of Justice (2010) Green paper on sentencing and rehabilitation.Justice Secretary Ken Clarke publication.

[17] Emily, B. K. (2002) The effectiveness of interventions to increase physical activity: a systematic review. American journal of preventive medicine, 22: 73-107.

[18] Pérez-Moreno, F., Cámara-Sánchez, M., Tremblay, J. F., Riera-Rubio, V. J., Gil-Paisán1, L., and Lucia, A. (2007) Benefits of Exercise in Spanish Prison Inmates. Int J Sports Med; 28: 1-7, 2007.

[19] WHO (2003) Health and Development Though Physical Activity and Sport. Geneva, Wito Document Production Services.

[20] American College of Sports Medicine (1995) Osteoporosis and Exercise: a position stand. MSSE, 27, 1-7.

[21] McAuley, E. and Morris, K. S., Advances in Physical Activity and Mental Health: Quality of Life. American Journal of Lifestyle Medicine. Vol. X No. X. 2007.

[22] Krause, S. J. and Stanwyck, C. A. (1998) Locus of control and life adjustment: Relationship among people with spinal cord injury. Rehabilitation Counselling Bulletin, 41 (3):162-172.
[23] Obadiora A. H. (2016) "The influence of sport participation on quality of life perceptions among inmates in Nigeria prisons." Journal of Sport for Development Vol. 4, 2016, pp. 36-43.

[24] Shephard, R. J., Aging and Exercise. In: Encyclopedia of Sports Medicine and Science, T. D. Fahey (Editor). Internet Society for Sport Science: http://sportsci.org. 7 March 1998.

[25] Oladimeji, B. Y. (2005) Psychological Assessment Techniques in Health Care. Obafemi Awolowo University Press Limited, Ile-Ife, Nigeria.

[26] Rejeski WJ, and Mihalko SL. (2001) Physical activity and quality of life in older adults. JGerontol A Biol Sci Med Sci. $56(2): 23-35$.

[27] Berger, B. (1996) 'Psychological benefits of an active lifestyle: what we know and what we need to know', Quest 48: 330 353.

[28] Obadiora, A. H. (2003) Correctional Recreation in the Psychological Treatment and Rehabilitation of Drug Dependents in Yaba Psychiatric Hospital and NeuroPsychiatric Hospital, Aro-Abeokuta. Unpublished M. A. Thesis submitted to the Department of Physical and Health Education, Obafemi Awolowo University, Ile-Ife, Nigeria. 